\title{
Extracorporeal Blood Purification and Organ Support in the Critically III Patient during COVID-19 Pandemic: Expert Review and Recommendation
}

\author{
Claudio Ronco ${ }^{\mathrm{a}, \mathrm{b}}$ Sean M. Bagshaw ${ }^{c}$ Rinaldo Bellomo ${ }^{\mathrm{d}, \mathrm{e}}$ William R. Clark ${ }^{f}$

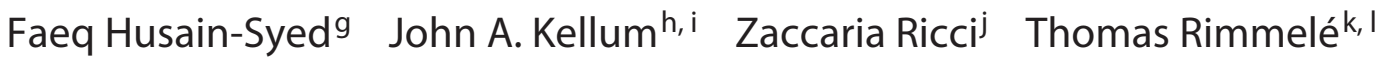 \\ Thiago Reis $^{\mathrm{m}, \mathrm{n}}$ Marlies Ostermann ${ }^{\mathrm{n}}$ \\ aDepartment of Nephrology, University of Padova, Padova, Italy; 'International Renal Research Institute (IRRIV), San \\ Bortolo Hospital, Vicenza, Italy; 'Department of Critical Care Medicine, Faculty of Medicine and Dentistry, University \\ of Alberta, Edmonton, AB, Canada; ${ }^{\mathrm{d} C e n t r e ~ f o r ~ I n t e g r a t e d ~ C r i t i c a l ~ C a r e, ~ T h e ~ U n i v e r s i t y ~ o f ~ M e l b o u r n e, ~ M e l b o u r n e, ~}$ \\ VIC, Australia; ${ }^{e}$ Department of Intensive Care, Austin Hospital, Melbourne, VIC, Australia; ${ }^{\mathrm{f} D a v i d s o n}$ School of \\ Chemical Engineering, Purdue University, West Lafayette, IN, USA; 9Department of Internal Medicine II, Division of \\ Nephrology, Pulmonology and Critical Care Medicine, University Hospital Giessen and Marburg, Giessen, Germany; \\ hDepartment of Critical Care Medicine, Center for Critical Care Nephrology, University of Pittsburgh, Pittsburgh, PA, \\ USA; 'Center for Critical Care Nephrology, University of Pittsburgh, Pittsburgh, PA, USA; jDepartment of Cardiology \\ and Cardiac Surgery, Pediatric Cardiac Intensive Care Unit, Bambino Gesù Children's Hospital, IRCCS, Rome, Italy; \\ kAnesthesiology and Critical Care Medicine, Edouard Herriot Hospital, Hospices Civils de Lyon, Lyon, France; 'EA \\ 7426 "Pathophysiology of Injury-induced Immunosuppression", Pi3, Hospices Civils de Lyon - BioMérieux - Claude \\ Bernard University Lyon, Lyon, France; mDepartment of Nephrology, Clinica de Doenças Renais de Brasilia, Brasilia, \\ Brazil; ' Department of Critical Care, King's College London, Guy's \& St Thomas' Hospital, London, UK
}

\section{Keywords}

Extracorporeal organ support - Continuous renal replacement therapies · Hemoperfusion · Hemoadsorption · Cytokine removal

\footnotetext{
Abstract

Critically ill COVID-19 patients are generally admitted to the ICU for respiratory insufficiency which can evolve into a multiple-organ dysfunction syndrome requiring extracorporeal organ support. Ongoing advances in technology and science and progress in information technology support the development of integrated multi-organ support platforms for personalized treatment according to the changing needs
}

of the patient. Based on pathophysiological derangements observed in COVID-19 patients, a rationale emerges for sequential extracorporeal therapies designed to remove inflammatory mediators and support different organ systems. In the absence of vaccines or direct therapy for COVID-19, extracorporeal therapies could represent an option to prevent organ failure and improve survival. The enormous demand in care for COVID-19 patients requires an immediate response from the scientific community. Thus, a detailed review of the available technology is provided by experts followed by a series of recommendation based on current experience and opinions, while waiting for generation of robust evidence from trials.

(c) 2020 S. Karger AG, Basel

$\begin{aligned} & \text { karger@karger.com } \\ & \text { www.karger.com/bpu }\end{aligned}$
Karger ${ }^{\prime /}$

Dr. Marlies Ostermann

King's College London, Department of Critical Care

School of Medical Education, Guy's and St Thomas' NHS Foundation Trust London SE1 7EH (UK)

Marlies.Ostermann@gstt.nhs.uk 


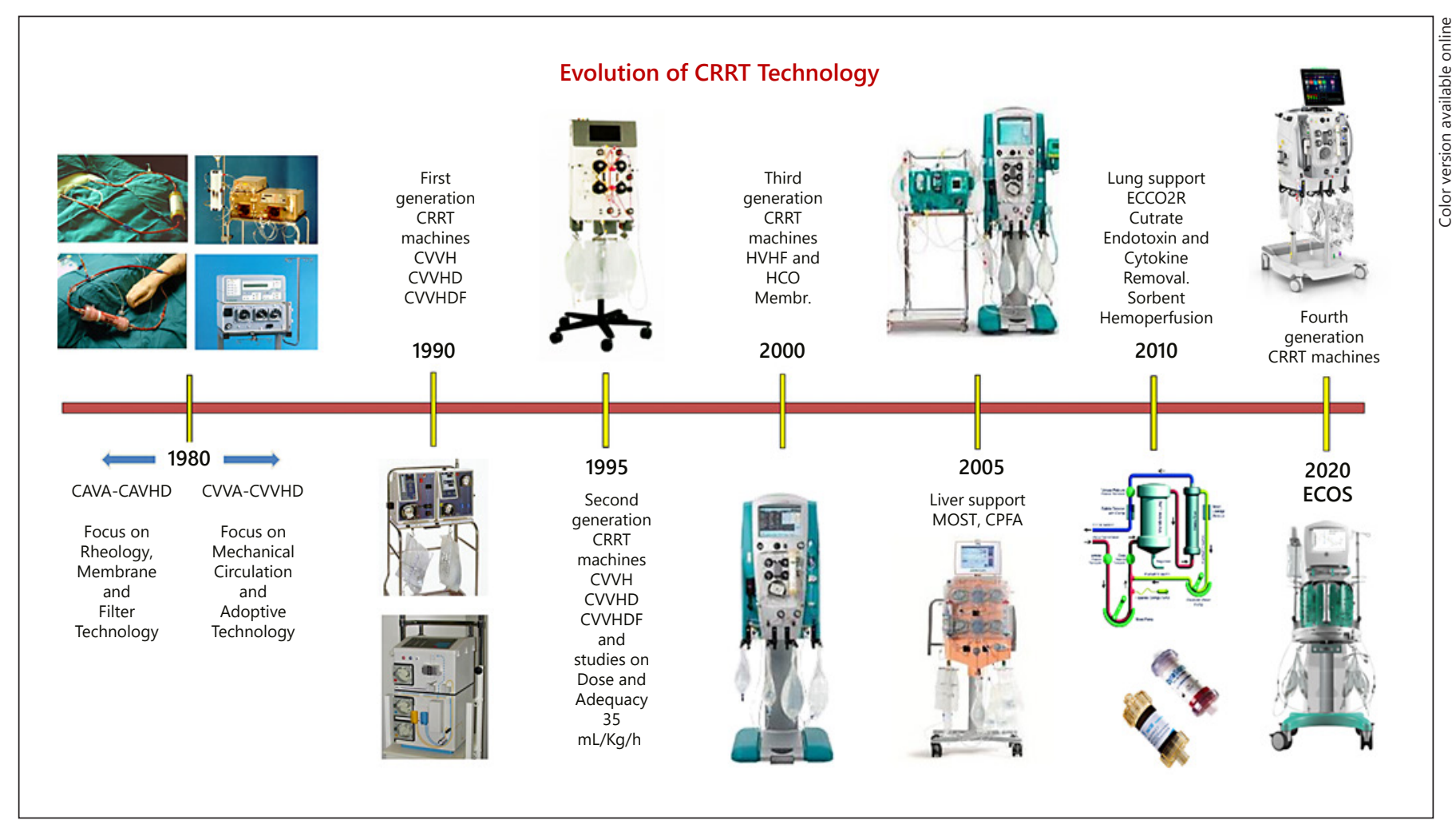

Fig. 1. A complete overview of 40 years of evolution in technology for extracorporeal therapies in the critically ill patient (modified from Ref. [3]). CAVHD, continuous arteriovenous hemodialysis; CAVHDF, continuous arterio-venous hemofilration; CVVH, continuous veno-venous hemofiltration; CVVHD, continuous veno-

\section{The COVID-19 Pandemic}

The World Health Organization declared COVID-19 a pandemic. Although the vast majority of COVID positive patients suffer from mild or no symptoms, a proportion of them require hospitalization or even admission to intensive care units (ICUs). These patients may develop acute kidney injury (AKI) and multiple organ failure (MOF) and may require extracorporeal organ support (ECOS) [1]. Kidney involvement in COVID-19 patients may precede, follow, or be concomitant with other organ system failure, and this situation may require fully competent and trained personnel to implement all possible therapeutic options for critically ill patients.

The evolution of continuous renal replacement therapies (CRRTs) from the initial description to the current technology $[2-6,8]$ has permitted worldwide use of extracorporeal therapies in critically ill patients (Fig. 1). In intensive care, severe AKI occurs mostly in the context of MOF. The term multiple organ support therapy (MOST), venous hemodialysis; CVVHDF, continuous veno-venous hemodiafiltration; CRRT, continuous renal replacement therapy; MOST, multi-organ support therapy; CPFA, coupled plasma filtration adsorption; $\mathrm{ECCO}_{2} \mathrm{R}$, extracorporeal $\mathrm{CO}_{2}$ removal; HCO, high cut-off.

now termed "Extracorporeal Organ Support" (ECOS), encompasses all forms of organ support by an extracorporeal circuit (for instance, renal replacement therapies [RRTs], extracorporeal $\mathrm{CO}_{2}$ removal $\left[\mathrm{ECCO}_{2} \mathrm{R}\right]$, venoarterial or veno-venous [VV] extracorporeal membrane oxygenation [ECMO], liver support systems, hemoperfusion, and various blood purification devices) [9]. Significant advances in technology and science resulted in the development of new biomaterial, membrane design, and anticoagulation techniques [10], allowing for optimization of treatment dose and modality $[11,12]$. The possible role of extracorporeal techniques in restoring a balanced immune response by eliminating/deactivating inflammatory mediators was explored [13]. The strategies included high-volume hemofiltration (HVHF), hemoperfusion, plasma exchange, coupled plasma filtration adsorption (CPFA), and the use of high cut-off (HCO) membranes and membranes with enhanced adsorption properties. In parallel, other forms of ECOS were developed, including $\mathrm{ECCO}_{2} \mathrm{R}, \mathrm{ECMO}$, ventricular assist devices, and extra-
18

Blood Purif 2021;50:17-27 DOI: $10.1159 / 000508125$
Ronco et al. 
corporeal liver support systems [9] (Fig. 1). Gradually, the status of RRT was elevated from simple renal support to a platform facilitating individualized multiple organ support (Fig. 2).

\section{Rationale for ECOS in COVID-19 Patients}

COVID-19 patients admitted to the ICU display a range of symptoms and organ dysfunction of varying degrees severity. While the majority have pneumonia with single-organ failure, others suffer from a significant derangement of the immune system, producing a cytokine storm and organ damage consequent to cellular injury. Furthermore, severe coagulation disorders sometimes mimics disseminated intravascular coagulation. Continuous and intermittent modalities are not "all or none" approaches to the provision of RRT [12]. Rather, a chosen modality of RRT necessitates thoughtful application to deliver the right therapy for the right patient at the right time. It is also important to recognize that patients may need to transition across modalities. There has been much debate about the apparent lack of differences in efficacy and effectiveness of continuous and intermittent modalities in clinical trials, and no specific evidence is provided for COVID-19 patients. However, confidence in inferences from these data for patient care is limited due to challenges in trial design (i.e., overestimated treatment effects), trial performance (i.e., quality of RRT applied across trials), selection bias of patients enrolled (i.e., lack of equipoise to enrol very sick patients), and non-patientrelated biases guiding practice (i.e., clinical service and costs). As such, continuous and the various forms of intermittent therapies should be considered complementary, recognizing neither modality will likely ever show clear evidence of survival advantage across all patients [7, 14, 15]. In addition, all RRT modalities have important adverse effects. They are unselective, resulting in unrecognized losses of electrolytes, nutrients, and drugs, including antibiotics. Where available, therapeutic drug monitoring should be considered. Other adverse effects include complications related to line insertion and side effects from anticoagulation. Finally, RRT does not provide any of the endocrine and metabolic functions of the kidneys. Despite the above considerations, there are particular clinical circumstances where a specific RRT modality would be preferable $[7,16]$. In COVID-19 patients with marked hemodynamic instability and/or refractory fluid overload, aggressive extracorporeal ultrafiltration can precipitate or worsen hypotension or decrease cardiac output or both,

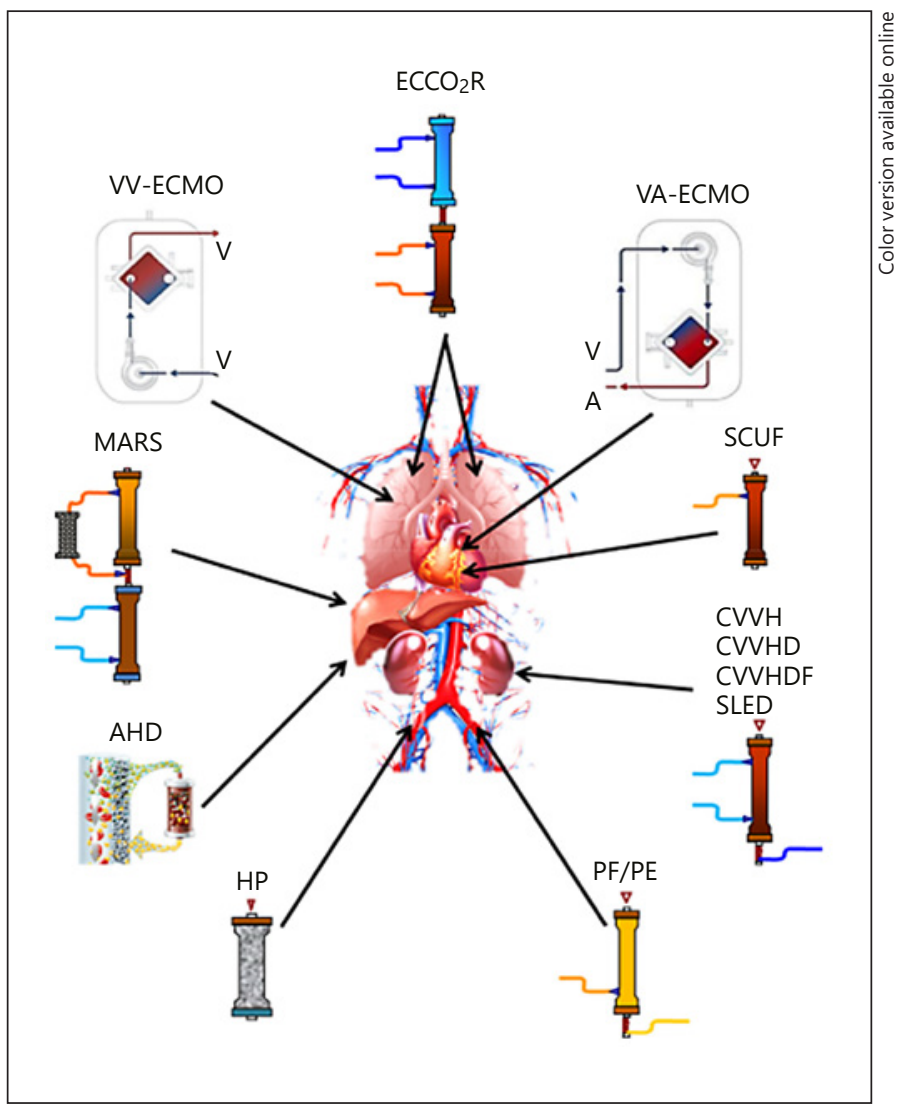

Fig. 2. Schematic representation of different ECOS systems. ECOS, extracorporeal organ support; $\mathrm{CVVH}$, continuous veno-venous hemofiltration; CVVHD, continuous veno-venous hemodialysis; CVVHDF, continuous veno-venous hemodiafiltration; CRRT, continuous renal replacement therapy; SLED, slow extended dialysis; SCUF, slow continuous ultrafiltration; CPFA, coupled plasma filtration adsorption; $\mathrm{ECCO}_{2} \mathrm{R}$, extracorporeal $\mathrm{CO}_{2}$ removal; VA-ECMO, veno-arterial extracorporeal membrane oxygenation; VV-ECMO, veno-venous extracorporeal membrane oxygenation; AHD, adsorption hemodialysis; HP, hemoperfusion; PF, plasmafiltration; PE, plasma exchange.

and delay recovery. Rapid shifts in blood osmolality may precipitate dangerous iatrogenic complications [17]. In these circumstances, there is a strong physiological rationale for initial support with CRRT to offer greater hemodynamic tolerance, consistency in ultrafiltration, and less metabolic and osmotic fluctuations [7, 16]. This extends to patients supported by concomitant ECOS (i.e., VVECMO for severe respiratory failure), where initial therapy with CRRT is better tolerated $[16,18]$. Alternatively, forms of prolonged and conventional intermittent RRT have an important complementary role in the support of critically ill patients with COVID-19 infection. These patients may frequently require mobilization and pronation 
to improve pulmonary gas exchange, and in these circumstances, treatments of 8-12 h may represent a good compromise between continuous and intermittent modalities. Similarly, among patients recovering from critical illness, the transition from CRRT to prolonged intermittent RRT may be advantageous, although no data are available on survival, kidney recovery, or long-term dialysis dependence [19-23]. COVID-19 patients have a tendency to develop a severe inflammatory state and possibly a cytokine release syndrome that may affect kidney function downstream in the time course of the syndrome. Although the optimal time for RRT initiation remains uncertain, observation of frequent episodes of oliguria and dangerous fluid overload during ICU stay suggests an early application, especially in case of inability to maintain adequate fluid balance. Sometimes RRT and ECMO are simultaneously run, and thus, an effort should be made in the future to merge these therapies into a unified platform [24] to reduce nurse workload and risk of errors due to poor compatibility or integration of different systems.

\section{ECOS Modifications in Relation to COVID-19 Requirements}

In COVID-19 patients, recent platforms allow circuit adjustment to perform different ECOS techniques besides RRT. Although there are only few reports of liver dysfunction in COVID-19 patients, special extracorporeal therapies are available for liver support, if needed [25-28]. Conjugated or unconjugated bilirubin, bile acids, phenols, fatty acids, cytokines, ammonia, or amino acids can be effectively removed by high-volume plasmapheresis, improving liver function through amelioration of the inflammatory response [29]. For the same purpose, double plasma molecular adsorption system and sequential half-dose plasma exchange have been utilized [30]. The use of hemoperfusion is expanding, thanks to new biocompatible sorbent cartridges. Removal of humoral mediators and cytokines with different columns (CytoSorb $^{\circledR}$, Cytosorbents, NJ, USA, and HA380, Jafron, China) has been beneficial and improved survival in different conditions [31, 32].

Supportive therapy and lung-protective ventilation are the current standard of care for COVID-19 patients with severe respiratory impairment and acute respiratory distress syndrome (ARDS). This approach may limit ventilation-induced lung injury, but it may be associated with insufficient correction of hypercapnia and respiratory acidosis [33].
The technique of $\mathrm{ECCO}_{2} \mathrm{R}$ has been introduced for hypercapnic respiratory failure not requiring significant oxygen support. In general, $\mathrm{CO}_{2}$ is produced at a rate of 3-6 $\mathrm{mL} / \mathrm{kg} / \mathrm{min}\left(1 \mathrm{~L}\right.$ arterial blood with a partial $\mathrm{CO}_{2} 40 \mathrm{~mm}$ $\mathrm{Hg}$ contains $500 \mathrm{~mL} \mathrm{CO}_{2}$ ) and has a steep linear dissociation curve without saturation. As such, $\mathrm{CO}_{2}$ diffuses from blood more efficiently than $\mathrm{O}_{2}[34,35]$. The effective amount of extracorporeal $\mathrm{CO}_{2}$ removal from patients depends on blood flow. Studies have shown progressive $\mathrm{CO}_{2}$ removal until blood flow of $800-1,000 \mathrm{~mL} / \mathrm{min}$ where a ceiling is reached. Low blood flow $\mathrm{ECCO}_{2} \mathrm{R}$ devices $(<0.5$ $\mathrm{L} / \mathrm{min}$ ) achieve partial $\mathrm{CO}_{2}$ removal. In the SUPERNOVA study, $\mathrm{ECCO}_{2} \mathrm{R}$ facilitated ultra-protective ventilation [36]. $\mathrm{ECCO}_{2} \mathrm{R}$ in combination with RRT has the potential to limit respiratory stress further by removing excess $\mathrm{CO}_{2}$ and compensating for respiratory acidosis, thus facilitating reduction in tidal volume $(<6 \mathrm{~mL} / \mathrm{kg})$ during lungprotective ventilation strategies $[37,38]$. This may be particularly appealing in patients with ARDS and concomitant AKI, where compensatory renal mechanisms are less effective in regulating acid-base homeostasis during hypercapnic acidosis. To date, several $\mathrm{ECCO}_{2} \mathrm{R}$ devices are available that can be used in conjunction with RRT hardware using variable blood flows [34, 39-52]. Techniques for improving $\mathrm{CO}_{2}$ removal with low blood flow devices include (i) RRT using low bicarbonate dialysate (as up to $65 \% \mathrm{CO}_{2}$ is carried as dissolved bicarbonate ions in plas$\mathrm{ma}$ and cleared at a rate close to that of urea); (ii) blood acidification during RRT (to increase $\mathrm{CO}_{2}$ release) and subsequent blood alkalization to correct acidosis [53]; (iii) coating of the membrane oxygenator with carbonic anhydrase (to convert bicarbonate and carbonic acid to $\mathrm{CO}_{2}$ and water) [54]; and (iv) electrodialysis coupled with a membrane oxygenator (to modulate blood electrolyte concentrations and promote bicarbonate conversion to $\mathrm{CO}_{2}$ ) [51]. Several clinical trials are ongoing to determine whether VV extracorporeal $\mathrm{CO}_{2}$ removal (VV-ECCO ${ }_{2} \mathrm{R}$ ) and lower tidal volume mechanical ventilation improves outcomes and is cost-effective, in comparison with standard care in patients receiving mechanical ventilation for acute hypoxemic respiratory failure.

\section{Extracorporeal Therapies in Cytokine Release Syndromes}

Although bacterial sepsis is not a common feature in COVID-19 patients, the immune response to the virus may lead in some patients to a similar pathophysiological condition of a "cytokine storm," that is, a severe cytokine
Ronco et al. 
release syndrome (CRS) with consequent organ dysfunction. Further organ damage may be induced by intravascular coagulation or micro/macro-thrombosis. Thus, life-threatening organ dysfunction caused by a dysregulated host response to infection depends not only on systemic inflammation due to innate immunity but also on a possible severe immunosuppression due to adaptive immunity. A pathophysiological rationale for extracorporeal therapies to restore "immune homeostasis" in CRS of different origin has been described [55]. Cascade hemofiltration, HVHF, plasmapheresis, hemoperfusion, $\mathrm{CPFA}$, high-adsorption hemofiltration, and $\mathrm{HCO} / \mathrm{medi}$ um cut-off (MCO) membranes have been proposed based on a pathophysiological rationale of cytokine and chemical mediator removal/modulation. Interestingly, in April 2020, the FDA temporarily authorized the emergency use of CytoSorb $300 \mathrm{~mL}$ device for the management of CRS in COVID-19 patients [56]. Based on bench performance testing and reported clinical experience, the FDA concluded that the CytoSorb device may be effective at treating certain patients with confirmed COVID-19 by removing various pro-inflammatory cytokines from their blood. Therefore, these therapies, although considered as "under scientific investigation," "salvage," or "compassionate use" interventions, still represent an option for severe CRS and, in particular, for COVID-19 patients where pharmacological alternatives are lacking. The mechanisms by which these techniques might exert beneficial effects remain poorly understood. The nonspecific or specific removal of some damage-associated molecular patterns and/or pathogen-associated molecular patterns most likely plays a key role in the modulation of the inflammatory response to sepsis. This removal may result in a decrease of the peaks of cytokine concentrations and/ or a modification of the cytokine/chemokine ratio from the tissues to the blood, positively impacting the leukocyte trafficking $[57,58]$. However, patients are not homogenous in terms of their inflammatory phenotype and have widely varying levels of cytokines in their blood (e.g., IL-6 can range from $<10$ to $>1$ million $\mathrm{pg} / \mathrm{mL}$ ) [59]. Applying blood purification to all patients may be beneficial for some and have no effect or even be injurious to others. Therefore, specific criteria should be defined. Other mechanisms such as direct adsorption of activated leukocytes and other cells involved in the immune response are also possibly involved [60]. CD14 expression on monocytes, oxidative burst, and the phagocytosis capacity of granulocytes may represent another mechanism. While HVHF was able to prevent in vitro sepsis-induced endotoxin hypo-responsiveness in animals [61], in humans,
HVHF and a HVHF cascade system did not result in survival benefits $[62,63]$. CPFA has also been utilized to interfere with the host immune response by removing mediators and/or by modifying immune cell phenotype and function. In a pilot study in septic patients, CPFA was more efficient than HVHF in reversing sepsis-induced immunoparalysis [64]. It increased the expression of HLA-DR on monocytes and restored lipopolysaccharideinduced TNF production. However, recently, the COMPACT-2 trial (NCT 01639664), evaluating CPFA in septic shock, was prematurely stopped due to increased early mortality in patients receiving CPFA compared to the control group. Plasmapheresis, plasma exchange, and related techniques have not been extensively evaluated for this indication. Nevertheless, it has been suggested that these therapies might be beneficial in patients with Gramnegative sepsis and when initiated early [65]. Nonetheless, no RCTs have been able to demonstrate a beneficial effect. Recently, the use of double plasmafiltration molecular adsorption system has been described for the above-mentioned indications in a small trial [30]. Hemoperfusion is a method of blood purification based on the interaction between a sorbent and target molecules. Several types of hemoperfusion cartridges, targeting endotoxins or cytokines, are available and are currently assessed across the world. Zhou et al. [66] reported in a meta-analysis that the beneficial effect of blood purification on mortality was mainly driven by the results of studies assessing hemoperfusion with polymyxin-B (PMXHP, Toraymyxin ${ }^{\circledR}$, Japan). In addition to hemodynamic and respiratory improvements, the EUPHAS trial suggested a survival benefit for septic patients receiving this therapy [67]. Unfortunately, the subsequent ABDOMIX and EUPHRATES trials did not confirm these promising findings $[68,69]$. In a post hoc analysis of EUPHRATES however, patients with septic shock and an endotoxin activity assay $\geq 0.6$ to 0.89 had significant benefits with PMX-HP treatment in the form of mean arterial pressure, ventilator-free days, and mortality [70]. A large RCT with CytoSorb $^{\circledR}$ (Cytosorbents, NJ, USA) involving 100 patients with sepsis/septic shock and acute lung injury found $5-18 \%$ single-pass removal of IL-6, but no lowering of IL-6 levels with treatment [71]. Another study in 30 patients comparing CytoSorb ${ }^{\circledR}$ versus standard care during cardiopulmonary bypass surgery showed no decrease in pro- or anti-inflammatory cytokines nor an improvement in relevant clinical outcomes [72]. In vitro measurement of 27 inflammatory mediators compared CytoSorb ${ }^{\circledR}$ with a PMX-HPng device and a recently developed adsorptive hemofiltration membrane (oXiris ${ }^{\circledR}$ ) 
[73]. The study showed that oXiris ${ }^{\circledR}$ was the only device to remove both endotoxin and cytokines with similar endotoxin removal to PMX-HP and similar cytokine removal to CytoSorb ${ }^{\circledR}$. However, to date, no RCTs exploring the oXiris ${ }^{\circledR}$ membrane have been performed. Filters with larger pore size allowing better removal of middle molecules in vitro have also been proposed for blood purification in sepsis [74]. However, a recent double-blind RCT found no beneficial effect in ICU patients with MOF [75]. A series of reports have also been published on the utility of hemoperfusion with neutro-macroporous resin device (HA-330/380, Jafron, China) in patients with sepsis $[76,77]$. Beneficial effects seem to be related to a significant removal of circulating cytokines. COVID-19 patients may have superimposed sepsis; however, the mechanism of organ damage seems to be quite similar to the immune dysregulation and the cytokine release syndrome observed in septic patients. For this reason, techniques such as PMX-HP, CytoSorb, and HA380 cartridge are used in COVID-19 patients as predicate therapies. Single-center reports of beneficial effects and reduced progression of the disease toward multiple organ dysfunction have been presented in meetings, but solid evidence is still lacking. There is also missing evidence on the use of drugs of any type for the virus infection. For the moment, the pathophysiological rationale is the only reason to suggest the application of these methods, and a case-by-case evaluation is advised, although if such treatments are being considered, it seems logical to apply them early [55].

\section{Native and Artificial Organ Interactions in COVID-19 Patients}

COVID-19 infection may lead to a cascade with a CTSmediated multiple organ dysfunction. While organ crosstalk has been well described in the literature, the effects of different types of ECOS on native organ systems are less well known [9]. For example, more than $70 \%$ of patients receiving ECMO develop AKI, and the majority are treated with RRT [18]. Although there are multiple reasons for $\mathrm{AKI}$ in patients who need ECMO, the exact contribution from ECMO support per se is unknown. Potential contributing factors may be hemolysis, malposition of the cannula leading to renal congestion, iatrogenic plaque rupture during arterial cannulation, and inflammatory reactions in response to blood contact with an artificial membrane. There may also be other more indirect effects; for instance, the pharmacokinetics of antibiotics and sed- atives may be altered during ECOS, leading to under- and overdosing [9]. The interaction between different types of artificial organ support needs also to be considered. For instance, ECMO flow is often difficult to maintain during rapid volume removal, so slowing fluid removal with CRRT is usually better tolerated by both the patient and the ECMO circuit. Detailed knowledge of the advantages and drawbacks of combining different types of ECOS and their risks and benefits is essential [18].

\section{Rationale for Extracorporeal Therapies in COVID-19 Patients}

During the COVID-19 pandemic, several patients admitted to the ICU may develop severe MOF at a later stage of the illness. Direct kidney involvement in COVID-19 infection has an overall low prevalence [78], but when present, it requires specific kidney support and restoration of physiological targets, allowing for recovery and repair. Several possible pathways have been identified, possibly leading to kidney damage. These have suggested the use of extracorporeal support and different blood purification strategies to prevent organ damage, to protect from further insults, and to support organ dysfunction [1]. A significant proportion of COVID-19 patients admitted to the ICU develop a CRS also known as "cytokine storm," with capillary leak syndrome and lung, heart, and kidney dysfunction. Among other mediators, interleukin-6 typically increases together with ferritin and C-reactive protein, and this is considered also a risk factor for developing ARDS [79]. Furthermore, the clinical picture is characterized by severe hypercoagulability. It has been suggested that the use of invasive mechanical ventilation and ECMO may further stimulate the inflammatory response. Cytokine overproduction is involved in lung-kidney and heart-kidney bidirectional interaction. Acute viral cardiomyopathy may in fact contribute to renal congestion and hypoperfusion, while renal medullary hypoxia in ARDS represents an additional insult to tubular cells [80-82]. Fluid expansion may lead to positive fluid balance in COVID-19 patients with detrimental effects on pulmonary gas exchange, cardiac function, and ultimately kidney function. Finally, superimposed infections may occur during ICU stay. In case of COVID-19 infection and CRS, with suspected or confirmed superimposed Gram-negative bacterial infections, the use of PMX-HP is indicated in the early phases to provide endotoxin adsorption [10]. PMX-HP should be used for 2 subsequent days. If CRS is present, this treatment should be followed
Ronco et al. 


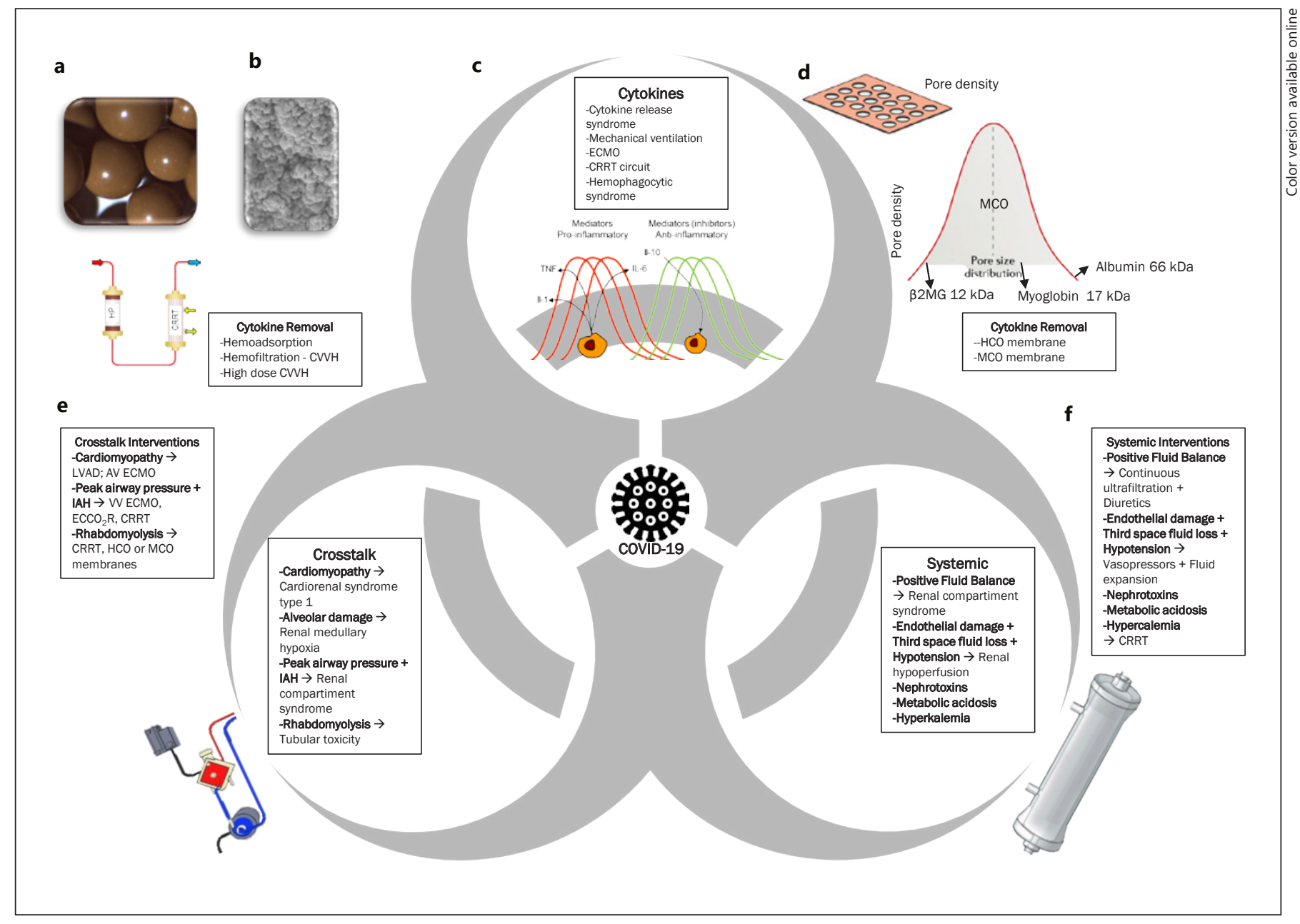

Fig. 3. Pathways of kidney damage and proposed treatments in COVID-19 infections. Didactically 3 broad aspects are involved in COVID-19-associated AKI. Bidirectional involvement of each element occurs, represented by Set Theory and the presence of intersections. Treatment strategies also influence different elements simultaneously. a Neutro-macroporous resin adsorbing beads magnified picture. b Bead on transmission electron microscopy. c Cytokine release syndrome and other triggers for cytokine generation. $\mathbf{d} \mathrm{MCO}$ has more uniformity in pore size distribution and pore density; these characteristics enable the membrane to effectively remove middle molecules in the range of most cytokines

by methods for cytokine adsorption (CytoSorb, Cytosorbents, NJ, USA; HA-380, Jafron, China; and oXiris, Baxter, Deerfield, IL, USA), and if organ support is required, CRRT should be implemented in conjunction or afterward. Such treatment of endotoxin removal, cytokine removal, and organ support along the course of the ICU stay is referred to as sequential extracorporeal therapy. Thus, ECOS represents the perfect combination of techniques to provide blood purification in COVID-19 pa- with tolerable albumin loss. e ECMO circuit. f Filter used in CRRT for fluid balance control, removal of nephrotoxins, correction of hyperkalemia, and metabolic acidosis. AKI, acute kidney injury; AV ECMO, arteriovenous ECMO; $\beta 2 \mathrm{MG}, \beta 2$ microglobulin; CRRT, continuous renal replacement therapy; $\mathrm{CVVH}$, continuous veno-venous hemofiltration; $\mathrm{ECCO}_{2} \mathrm{R}$, extracorporeal carbon dioxide removal; ECMO, extracorporeal membrane oxygenation; $\mathrm{HCO}$, high cut-off; MCO, medium cut-off membrane; IAH, intraabdominal hypertension; IL, interleukin; $\mathrm{kDa}$, kilodalton; LVAD, left ventricular assist device; TNF, tumor necrosis factor; VV ECMO, veno-venous ECMO. 
Practical Recommendation for Critically III COVID-19 Patients

When extracorporeal therapies are prescribed in COVID-19 patients, we recommend the use of jugular double-lumen catheters of adequate size to allow sufficient blood flow regardless of type of treatment. It is fundamental to anchor the catheter firmly to avoid accidental disconnection during mobilization and pronation as frequently required in these patients. A prothrombotic status requires incremental dosage of anticoagulation both to maintain circuit patency and to manage the thrombophilia of the patient. In the case of unfractionated heparin, we start with $10 \mathrm{IU} / \mathrm{kg} / \mathrm{h}$, but in some patients, a higher dosage of up to 15 and $20 \mathrm{IU} / \mathrm{kg} / \mathrm{h}$ may be required to ensure circuit patency. Independent of extracorporeal therapy, patients may be treated with low molecular weight heparin to prevent episodes of micro- or macro-embolism which is frequently observed as a complication of COVID-19 infection. Blood flows above $150 \mathrm{~mL} / \mathrm{min}$ and the use of diffusive techniques (CVVHD) with minimal filtration fraction further help avoiding circuit clotting. If long-term treatment is planned, regional citrate anticoagulation can be prescribed, although no evidence of superior outcomes has been provided. Furthermore, some centers find this technique too complicated or requiring too many interventions at the bedside. COVID-19 areas are often already overwhelmed by procedures and further nurse load should be avoided. If possible, later generation CRRT machines should be used with the possibility of modifying circuit characteristics during treatment or directing spent dialysate directly to the drain, avoiding frequent bag changes [84]. According to current experience and in the absence of any specific therapy besides supportive measures, we suggest that cytokine removal strategies should be reserved for COVID-19 patients with evidence of high circulating cytokines such as IL-6 and IL-8, a biochemically determined inflammatory status, high SOFA score, clinical symptoms of hemodynamic instability requiring vasopressors, and initial signs of immune dysregulation or disorders of coagulation cascade. Markers such as plasma ferritin or urinary biomarkers of kidney stress may also be useful to identify cases of hyper-inflammation. Clinical criteria alone may be surrogates of hyper-inflammation, but they should be evaluated case by case. In the future, genetic profiling may guide the initiation of this therapeutic strategy for specific patients. If PMX-HP is indicated for suspected sepsis (high procalcitonin and/or positive bacterial culture) or confirmed by elevated endotoxin activity assay, 2-h sessions in 2 subsequent days are advised. A third session might be required in some patients. These sessions may or may not be followed by hemoperfusion with CytoSorb or HA-380. If hemoperfusion is indicated for removal of cytokines, multiple sessions can be scheduled in subsequent days. In all cases, anticoagulation should be provided to maintain circuit patency, and a blood flow rate higher than $120 \mathrm{~mL} / \mathrm{min}$ should be prescribed. In addition, oXiris or polymethylmetacrylate membranes can also be utilized in CRRT mode for the purpose of cytokine removal. When RRT is indicated, this can be performed with current membranes, with $\mathrm{HCO}$ or MCO membranes both in continuous or intermittent modalities [1, 13, 79-89]. Due to frequent mobilization and pronation, patients may be treated with prolonged intermitted sessions (PIRRT) to allow nursing maneuvers. Because of severe hemodynamic instability and the need to control the patients' fluid balance, fluid removal should be carefully scheduled to avoid hypotension that could worsen kidney injury or delay recovery. In the absence of established drugs or vaccines for COVID-19, the pathophysiological rationale beyond typical supportive therapies, such as ventilation, may suggest the application of ECOS techniques in patients who respond to clinical or biochemical criteria of eligibility. We are fully aware that these recommendations are not yet based on solid evidence but rather on clinical experience matured on the field. Specific prevention and protection measures to avoid development of organ failure from cytokine storm, or targeted organ support therapies might help critically ill patients with COVID-19 where there is little or nothing except supportive treatment. Clinical conditions (shock-like syndrome with vasopressor requirement, capillary leak syndrome, myocarditis, and ARDS) and laboratory criteria (IL-6 and inflammatory markers) and AKI biomarkers could represent the triggers to implement single or various extracorporeal treatments in sequence. In COVID-19 patients, all these new features and advances may represent a real option at a time when pharmacological and vaccine options are close to zero.

\section{Disclosure Statement}

C.R. has received speaker and consulting honoraria from Baxter, Medtronic, Fresenius, B. Braun, Jafron, and Cytosorbents. T.R. has received speaker and consulting honoraria from Fresenius Medical Care, Baxter Healthcare Corp, Biomérieux, Medtronic, Nikkiso, and B. Braun. R.B. has received grants and speaking fees from Baxter. J.K. discloses grant support and/or consulting fees from Baxter, NxStage, Fresenius, Biomérieux, and Cytosorbents. M.O. received grant support, consulting fees, and/or speaker honoraria from Fresenius Medical, NxStage, and Baxter. W.C. used to be an employee of Baxter.
Ronco et al. 


\section{Funding Sources}

The authors did not receive any funding.

\section{Author Contributions}

All authors equally contributed to the content, literature search, and editing and revision of the manuscript. C.R. and M.O. wrote the manuscript and provided the figures.

\section{References}

1 Ronco C, Reis T. Kidney involvement in Covid-19 patients and the role of extracorporeal therapies. Nat Rev Nephrol. 2020 Apr 9. DOI: 10.1038/s41581-020-0284-7.

2 Kramer P, Wigger W, Rieger J, Matthaei D, Scheler F [Arteriovenous haemofiltration: a new and simple method for treatment of overhydrated patients resistant to diuretics]. Klin Wochenschr. 1977;55(22):1121-2.

3 Ronco C. Continuous renal replacement therapy: forty-year anniversary. Int J Artif Organs. 2017 May 31;40(6):257-64.

4 Ronco C, Garzotto F, Brendolan A, Zanella M, Bellettato M, Vedovato S, et al. Continuous renal replacement therapy in neonates and small infants: development and first-inhuman use of a miniaturised machine (CARPEDIEM). Lancet. 2014;383(9931):1807-13.

5 Villa G, Neri M, Bellomo R, Cerda J, De Gaudio AR, De Rosa S, et al. Nomenclature for renal replacement therapy and blood purification techniques in critically ill patients: practical applications. Crit Care. 2016;20(1): 283.

6 Schneider A, Ostermann M. The AKI glossary. Intensive Care Med. 2017;43(6):893-7.

7 Kidney Disease: Improving Global Outcomes (KDIGO) Acute Kidney Injury Work Group. KDIGO clinical practice guideline for acute kidney injury. Kidney Int. 2012;2012:1-138.

8 Ronco C, Ricci Z, De Backer D, Kellum JA, Taccone FS, Joannidis M, et al. Renal replacement therapy in acute kidney injury: controversy and consensus. Crit Care. 2015;19:146.

9 Husain-Syed F, Ricci Z, Brodie D, Vincent JL, Ranieri VM, Slutsky AS, et al. Extracorporeal organ support (ECOS) in critical illness and acute kidney injury: from native to artificial organ crosstalk. Intensive Care Med. 2018; 44(9):1447-59.

10 Ostermann M. Techniques and modalities of continuous renal replacement therapy. Contrib Nephrol. 2018;194:51-9.

11 Ronco C, Bellomo R, Homel P, Brendolan A, Dan M, Piccinni P, et al. Effects of different doses in continuous veno-venous haemofiltration on outcomes of acute renal failure: a prospective randomised trial. Lancet. 2000; 356(9223):26-30.

12 Bagshaw SM, Darmon M, Ostermann M, Finkelstein FO, Wald R, Tolwani AJ, et al. Current state of the art for renal replacement therapy in critically ill patients with acute kidney injury. Intensive Care Med. 2017;43(6):84154.
13 Ankawi G, Neri M, Zhang J, Breglia A, Ricci $\mathrm{Z}$, Ronco C. Extracorporeal techniques for the treatment of critically ill patients with sepsis beyond conventional blood purification therapy: the promises and the pitfalls. Crit Care. 2018;22(1):262.

14 Schwenger V, Weigand MA, Hoffmann O, Dikow R, Kihm LP, Seckinger J, et al. Sustained low efficiency dialysis using a singlepass batch system in acute kidney injury: a randomized interventional trial: the REnal Replacement Therapy Study in Intensive Care Unit PatiEnts. Crit Care. 2012;16(4):R140.

15 Zhang L, Yang J, Eastwood GM, Zhu G, Tanaka A, Bellomo R. Extended daily dialysis versus continuous renal replacement therapy for acute kidney injury: a meta-analysis. Am J Kidney Dis. 2015;66(2):322-30.

16 Ostermann M, Joannidis M, Pani A, Floris M, De Rosa S, Kellum JA, et al. Patient selection and timing of continuous renal replacement therapy. Blood Purif. 2016;42(3):224-37.

17 Davenport A, Will EJ, Davison AM. Effect of renal replacement therapy on patients with combined acute renal and fulminant hepatic failure. Kidney Int Suppl. 1993;41:S245-51.

18 Ostermann M, Connor MJr, Kashani K. Continuous renal replacement therapy during extracorporeal membrane oxygenation: why, when and how? Curr Opin Crit Care. 2018; 24(6):493-503.

19 Bonnassieux M, Duclos A, Schneider AG, Schmidt A, Bénard S, Cancalon C, et al. Renal replacement therapy modality in the ICU and renal recovery at hospital discharge. Crit Care Med. 2018;46:e102-10.

20 Schneider AG, Bellomo R, Bagshaw SM, Glassford NJ, Lo S, Jun M, et al. Choice of renal replacement therapy modality and dialysis dependence after acute kidney injury: a systematic review and meta-analysis. Intensive Care Med. 2013;39(6):987-97.

21 Wald R, Shariff SZ, Adhikari NK, Bagshaw SM, Burns KE, Friedrich JO, et al. The association between renal replacement therapy modality and long-term outcomes among critically ill adults with acute kidney injury: a retrospective cohort study. Crit Care Med. 2014;42(4):868-77.

22 Chawla LS, Bellomo R, Bellomo R, Bihorac A, Goldstein SL, Siew ED, et al. Acute kidney disease and renal recovery: consensus report of the acute disease quality initiative (ADQI) 16 workgroup. Nat Rev Nephrol. 2017;13(4): $241-57$.
23 Liang KV, Sileanu FE, Clermont G, Murugan R, Pike F, Palevsky PM, et al. Modality of RRT and recovery of kidney function after AKI in patients surviving to hospital discharge. Clin J Am Soc Nephrol. 2016;11(1):30-8.

24 Cerdá J, Baldwin I, Honore PM, Villa G, Kellum JA, Ronco C, et al. Role of technology for the management of AKI in critically Ill patients: from adoptive technology to precision continuous renal replacement therapy. Blood Purif. 2016;42(3):248-65.

25 Bellmann R, Graziadei IW, Feistritzer C, Schwaighofer H, Stellaard F, Sturm E, et al. Treatment of refractory cholestatic pruritus after liver transplantation with albumin dialysis. Liver Transpl. 2004;10(1):107-14.

26 Saliba F, Camus C, Durand F, Mathurin P, Letierce A, Delafosse B, et al. Albumin dialysis with a noncell artificial liver support device in patients with acute liver failure: a randomized, controlled trial. Ann Intern Med. 2013; 159(8):522-31.

27 Bañares R, Nevens F, Larsen FS, Jalan R, Albillos A, Dollinger M, et al. Extracorporeal albumin dialysis with the molecular adsorbent recirculating system in acute-on-chronic liver failure: the RELIEF trial. Hepatology. 2013; 57(3):1153-62.

28 Sponholz C, Matthes K, Rupp D, Backaus W, Klammt S, Karailieva D, et al. Molecular adsorbent recirculating system and single-pass albumin dialysis in liver failure: a prospective, randomised crossover study. Crit Care. 2016; 20:2.

29 Larsen FS, Schmidt LE, Bernsmeier C, Rasmussen A, Isoniemi $\mathrm{H}$, Patel VC, et al. Highvolume plasma exchange in patients with acute liver failure: an open randomised controlled trial. J Hepatol. 2016;64(1):69-78.

30 Yao J, Li S, Zhou L, Luo L, Yuan L, Duan Z, et al. Therapeutic effect of double plasma molecular adsorption system and sequential halfdose plasma exchange in patients with $\mathrm{HBV}$ related acute-on-chronic liver failure. J Clin Apher. 2019 Aug;34(4):392-8.

31 Huang Z, Wang SR, Su W, Liu JY. Removal of humoral mediators and the effect on the survival of septic patients by hemoperfusion with neutral microporous resin column. Ther Apher Dial. 2010 Dec;14(6):596-602.

32 Hassan K, Kannmacher J, Wohlmuth P, Budde U, Schmoeckel M, Geidel S. Cytosorb adsorption during emergency cardiac operations in patients at high risk of bleeding. Ann Thorac Surg. 2019;108(1):45-51. 
33 Imai Y, Parodo J, Kajikawa O, de Perrot M, Fischer S, Edwards V, et al. Injurious mechanical ventilation and end-organ epithelial cell apoptosis and organ dysfunction in an experimental model of acute respiratory distress syndrome. JAMA. 2003;289(16):2104-12.

34 Duscio E, Cipulli F, Vasques F, Collino F, Rapetti F, Romitti F, et al. Xtracorporeal $\mathrm{CO} 2$ removal: the minimally invasive approach, theory, and practice. Crit Care Med. 2019; 47(1):33-40.

35 Combes A, Fanelli V, Pham T, Ranieri VM. Feasibility and safety of extracorporeal $\mathrm{CO} 2$ removal to enhance protective ventilation in acute respiratory distress syndrome: the SUPERNOVA study. Intensive Care Med Feb. 2019;45(5);592-600.

36 Morelli A, Del Sorbo L, Pesenti A, Ranieri VM, Fan E. Extracorporeal carbon dioxide removal (ECCO2R) in patients with acute respiratory failure. Intensive Care Med.2017; 43(4):519-30.

37 Fanelli V, Ranieri MV, Mancebo J, Moerer O, Quintel M, Morley S, et al. Feasibility and safety of low-flow extracorporeal carbon dioxide removal to facilitate ultra-protective ventilation in patients with moderate acute respiratory distress sindrome. Crit Care. 2016;20:36.

38 Nolte SH, Jonitz WJ, Grau J, Roth H, Assenbaum ER. Hemodialysis for extracorporeal bicarbonate/CO2 removal (ECBicCO2R) and apneic oxygenation for respiratory failure in the newborn. Theory and preliminary results in animal experiments. ASAIO Trans. 1989; 35(1):30-4.

39 Forster C, Schriewer J, John S, Eckardt KU, Willam C. Low-flow $\mathrm{CO} 2$ removal integrated into a renal-replacement circuit can reduce acidosis and decrease vasopressor requirements. Crit Care. 2013;17(4):R154.

40 Quintard JM, Barbot O, Thevenot F, de Matteis O, Benayoun L, Leibinger F. Partial extracorporeal carbon dioxide removal using a standard continuous renal replacement therapy device: a preliminary study. ASAIO J. 2014;60(5):564-9.

41 Allardet-Servent J, Castanier M, Signouret T, Soundaravelou R, Lepidi A, Seghboyan JM. Safety and efficacy of combined extracorporeal $\mathrm{CO} 2$ removal and renal replacement therapy in patients with acute respiratory distress syndrome and acute kidney injury: the pulmonary and renal support in acute respiratory distress syndrome study. Crit Care Med. 2015;43(12):2570-81.

42 Fanelli V, Cantaluppi V, Alessandri F, Costamagna A, Cappello P, Brazzi L, et al. Extracorporeal $\mathrm{CO} 2$ removal May improve renal function of patients with acute respiratory distress syndrome and acute kidney injury: an openlabel, interventional clinical trial. Am J Respir Crit Care Med. 2018;198(5):687-90.
43 Schmidt M, Jaber S, Zogheib E, Godet T, Capellier G, Combes A. Feasibility and safety of low-flow extracorporeal $\mathrm{CO} 2$ removal managed with a renal replacement platform to enhance lung-protective ventilation of patients with mild-to-moderate ARDS. Crit Care. 2018;22(1):122.

44 Chang BS, Garella S. Complete extracorporeal removal of metabolic carbon dioxide by alkali administration and dialysis in apnea. Int J Artif Organs. 1983;6(6):295-8.

45 Isobe J, Mizuno H, Matsunobe S, Shimizu Y, Ikada Y, Kishida A. A new type of low blood flow ECCO2R using a hemodialysis system in apneic states. ASAIO Trans. 1989;35(3):6389.

46 Cressoni M, Zanella A, Epp M, Corti I, Patroniti N, Kolobow T, et al. Decreasing pulmonary ventilation through bicarbonate ultrafiltration: an experimental study. Crit Care Med. 2009;37(9):2612-8.

47 Russ M, Deja M, Ott S, Bedarf J, Keckel T, Hiebl B, et al. Experimental high-volume hemofiltration with predilutional tris-hydroxymethylaminomethane for correction of low tidal volume ventilation-induced acidosis. Artif Organs. 2011;35(6):E108-118.

48 Zanella A, Mangili P, Giani M, Redaelli S, Scaravilli V, Castagna L, et al. Extracorporeal carbon dioxide removal through ventilation of acidified dialysate: an experimental study. J Heart Lung Transplant. 2014;33(5):536-41.

49 Godet T, Combes A, Zogheib E, Jabaudon M, Futier E, Slutsky AS, et al. Novel CO2 removal device driven by a renal-replacement system without hemofilter. A first step experimental validation. Anaesth Crit Care Pain Med. 2015;34(3):135-40.

50 Scaravilli V, Kreyer S, Linden K, Belenkiy S, Pesenti A, Zanella A, et al. Enhanced extracorporeal $\mathrm{CO} 2$ removal by regional blood acidification: effect of infusion of three metabolizable acids. ASAIO J. 2015;61(5):533-9.

51 Zanella A, Castagna L, Salerno D, Scaravilli V, Abd El Aziz El Sayed Deab S, Magni F, et al. Respiratory electrodialysis. A novel, highly efficient extracorporeal $\mathrm{CO} 2$ removal technique. Am J Respir Crit Care. 2015;192(6): 719-26.

52 Sharma AS, Weerwind PW, Bekers O, Wouters EM, Maessen JG. Carbon dioxide dialysis in a swine model utilizing systemic and regional anticoagulation. Intensive Care Med Exp. 2016;4(1):2.

53 Zanella A, Mangili P, Redaelli S, Scaravilli V, Giani M, Ferlicca D, et al. Regional blood acidification enhances extracorporeal carbon dioxide removal: a 48-hour animal study. Anesthesiology. 2014;120(2):416-24.

54 Arazawa DT, Kimmel JD, Finn MC, Federspiel WJ. Acidic sweep gas with carbonic anhydrase coated hollow fiber membranes synergistically accelerates $\mathrm{CO} 2$ removal from blood. Acta Biomater. 2015;25:143-9.

55 Ronco C, Bellomo R, Lonneman G. Sepsis: theory and therapies. N Engl J Med. $2003 \mathrm{Apr}$ $17 ; 348(16): 1600-2$
56 Ronco C, Tetta C, Mariano F, Wratten ML, Bonello $\mathrm{M}$, Bordoni $\mathrm{V}$, et al. Interpreting the mechanisms of continuous renal replacement therapy in sepsis: the peak concentration hypothesis. Artif Organs. 2003;27(9):792-801.

57 FDA approval document. Available from: https://www.fda.gov/medical-devices/emergency-situations-medical-devices/emergency-use-authorizations.

58 Peng ZY, Bishop JV, Wen XY, Elder MM, Zhou F, Chuasuwan A, et al. Modulation of chemokine gradients by apheresis redirects leukocyte trafficking to different compartments during sepsis, studies in a rat model. Crit Care. 2014;18:R141.

59 Kellum JA, Pike F, Yealy DM, Huang DT, Shapiro NI, Angus DC, et al. Relationship between alternative resuscitation strategies, host response and injury biomarkers, and outcome in septic shock: analysis of the protocolbased care for early septic shock study. Crit Care Med. 2017;45(3):438-45.

60 Rimmelé T, Kaynar AM, McLaughlin JN, Bishop JV, Fedorchak MV, Chuasuwan A, et al. Leukocyte capture and modulation of cellmediated immunity during human sepsis: an ex vivo study. Crit Care. 2013;17:R59.

61 Yekebas EF, Eisenberger CF, Ohnesorge $\mathrm{H}$, Saalmüller A, Elsner HA, Engelhardt M, et al. Attenuation of sepsis-related immunoparalysis by continuous veno-venous hemofiltration in experimental porcine pancreatitis. Crit Care Med. 2001;29:1423-30.

62 Joannes-Boyau O, Honoré PM, Perez P, Bagshaw SM, Grand H, Canivet JL, et al. Highvolume versus standard-volume haemofiltration for septic shock patients with acute kidney injury (IVOIRE study): a multicentre randomized controlled trial. Intensive Care Med. 2013;39:1535-46.

63 Quenot JP, Binquet C, Vinsonneau C, Barbar $S D$, Vinault S, Deckert V, et al. Very high volume hemofiltration with the Cascade system in septic shock patients. Intensive Care Med. 2015;41:2111-20.

64 Mao HJ, Yu S, Yu XB, Zhang B, Zhang L, Xu $\mathrm{XR}$, et al. Effects of coupled plasma filtration adsorption on immune function of patients with multiple organ dysfunction syndrome. Int J Artif Organs. 2009;32:31-8.

65 Busund R, Koukline V, Utrobin U, Nedashkovsky E. Plasmapheresis in severe sepsis and septic shock: a prospective, randomised, controlled trial. Intensive Care Med. 2002;28: 1434-9.

66 Zhou F, Peng Z, Murugan R, Kellum JA Blood purification and mortality in sepsis: a meta-analysis of randomized trials. Crit Care Med. 2013;41:2209-20.

67 Cruz DN, Antonelli M, Fumagalli R, Foltran F, Brienza N, Donati A, et al. Early use of polymyxin $B$ hemoperfusion in abdominal septic shock: the EUPHAS randomized controlled trial. JAMA. 2009;301:2445-52. 
68 Payen DM, Guilhot J, Launey Y, Lukaszewicz AC, Kaaki M, Veber B, et al. Early use of polymyxin $B$ hemoperfusion in patients with septic shock due to peritonitis: a multicenter randomized control trial. Intensive Care Med. 2015;41:975-84.

69 Dellinger RP, Bagshaw SM, Antonelli M, Foster DM, Klein DJ, Marshall JC, et al. Effect of targeted polymyxin B hemoperfusion on 28day mortality in patients with septic shock and elevated endotoxin level: the EUPHRATES randomized clinical trial. JAMA. 2018; 320:1455-63.

70 Klein DJ, Foster D, Walker PM, Bagshaw SM, Mekonnen H, Antonelli M. Polymyxin B hemoperfusion in endotoxemic septic shock patients without extreme endotoxemia: a post hoc analysis of the EUPHRATES trial. Intensive Care Med. 2018;44(12):2205-12.

71 Schädler D, Pausch C, Heise D, Meier-Hellmann A, Brederlau J, Weiler N, et al. The effect of a novel extracorporeal cytokine hemoadsorption device on IL-6 elimination in septic patients: a randomized controlled trial. PLoS One. 2017;12:e0187015.

72 Poli EC, Alberio L, Bauer-Doerries A, Marcucci C, Roumy A, Kirsch M, et al. Cytokine clearance with Cytosorb during cardiac surgery: a pilot randomized controlled trial. Crit Care. 2019;23(1):108.

73 Malard B, Lambert C, Kellum JA. In vitro comparison of the adsorption of inflammatory mediators by blood purification devices. Intensive Care Med Exp. 2018;6:12.
74 Atan R, Peck L, Visvanathan K, Skinner N, Eastwood G, Bellomo R, et al. High cut-off hemofiltration versus standard hemofiltration: effect on plasma cytokines. Int J Artif Organs. 2016;39:479-86.

75 Atan R, Peck L, Prowle J, Licari E, Eastwood GM, Storr M, et al. A double-blind randomized controlled trial of high cutoff versus standard hemofiltration in critically ill patients with acute kidney injury. Crit Care Med. 2018;46:e988-94.

76 Chu L, Li G, Yu Y, Bao X, Wei H, Hu M. Clinical effects of hemoperfusion combined with pulse high-volume hemofiltration on septic shock. Medicine. 2020 Feb;99(9):e19058.

77 Kaçar CK, Uzundere O, Kandemir D, Yektaş A. Efficacy of HA330 hemoperfusion adsorbent in patients followed in the intensive care unit for septic shock and acute kidney injury and treated with continuous venovenous hemodiafiltration as renal replacement therapy. Blood Purif. 2020 Jan 28:1-9.

78 Guan WJ, Ni ZY, Hu Y, Liang WH, Ou CQ, $\mathrm{He}$ JX. et al. Clinical characteristics of coronavirus disease 2019 in China. N Engl J Med. 2020;3(5):e208292.

79 Wu C, Chen X, Cai Y, Xia J, Zhou X, Xu S, et al. Risk factors associated with acute respiratory distress syndrome and death in patients with coronavirus disease 2019 pneumonia in Wuhan, China. JAMA Intern Med. 2020.

80 Panitchote A, Mehkri O, Hastings A, Hanane T, Demirjian S, Torbic H, et al. Factors associated with acute kidney injury in acute respiratory distress syndrome. Ann Intensive Care. 2019;9:74.
81 Husain-Syed F, Slutsky AS, Ronco C. Lungkidney cross-talk in the critically Ill patient. Am J Respir Crit Care Med. 2016;194:402-14.

82 Huang C, Wang Y, Li X, Ren L, Zhao J, Hu Y. et al. Clinical features of patients infected with 2019 novel coronavirus in Wuhan, China. Lancet. 2020;395;497-506.

83 Ronco C, Reis T, De Rosa S. Coronavirus epidemic and extracorporeal therapies in intensive care: si vis pacem para bellum. Blood $\mathrm{Pu}$ rif. 2020;49(3);255-8.

84 Girardot T, Schneider A, Rimmelé T. Blood purification techniques for sepsis and septic AKI. Semin Nephrol. 2019;39:505-14.

85 Bell M, Broman M, Joannes-Boyau O, Ronco C. Comparison of the accuracy of the novel PrisMax continuous renal replacement therapy system to the classic prismaflex system. Blood Purif. 2019;47(1-3):166-70.

86 Ronco C, Clark WR. Haemodialysis membranes. Nat Rev Nephrol. 2018 Jun;14(6):394410.

87 Ronco C, Marchionna N, Brendolan A, Neri M, Lorenzin A, Martínez Rueda AJ. Expanded haemodialysis: from operational mechanism to clinical results. Nephrol Dial Transplant. 2018 Oct 1;33(Suppl 1_3):iii41-7.

88 Romagnoli S, Ricci Z, Ronco C. CRRT for sepsis-induced acute kidney injury. Curr Opin Crit Care. 2018 Dec;24(6):483-92.

89 Clark WR, Neri M, Garzotto F, Goldstein SL, Ricci Z, Ronco C. The future of critical care: renal support in 2027. Crit Care. 2017;21:92. 